\title{
Suicide from a Cerbera odollam kernel
}

\section{Lee Eng Kiang}

Senior Consultant Intensive Care Medicine Ng Teng Fong General Hospital.

Corresponding Author: Lee Eng Kiang, Senior Consultant Intensive Care Medicine Ng Teng Fong General Hospital.

E-mail: drchittoria@yahoo.com

Received date: November 12 2019; Accepted date: December 20, 2019; Published date: January 02,2020

Citation: Lee Eng Kiang. (2020) Suicide from a Cerbera odollam kernel. J. Archives of Medical Case Reports and Case Study. 3(1); DOI: 10.31579/2692-9392/007

Copyright: ( 2020 Lee Eng Kiang, This is an open-access article distributed under the terms of the Creative Commons Attribution License, which permits unrestricted use, distribution, and reproduction in any medium, provided the original author and source are credited.

Abstract
We report the case of a 22 year-old female patient who died 24 hours after consuming 2 seeds of the mangrove
plant Cerbera odollam, locally known as the Pong pong tree from fatal dysrhythmia. This fruit is responsible for a
lot of suicidal deaths in Kerala, India but rarely in Singapore [1]. These seeds contain active cardiac glycosides
similar to digoxin which can result in fatal dysrhythmias and hyperkalaemia.
Key words: suicide; Pong Pong; Cerbera odollam; digoxin

Introduction

Suicide is the leading cause of death in Singapore for the age group ranging from 10 to 29 years. There are a total of 361 in 2017 and a male predominance of $66 \%$ of all the deaths.

The unfortunate patient is a 22 year old female who was known to have mood disorders and also depression for 4 years.

She had been on regular follow ups at the psychiatric and psychological
Clinics and previous suicidal attempts. She admitted that she had taken 2 seeds of the Cerbera odollam, figure 1 or locally known as the Pong Pong tree on the night prior to the admission to the emergency department. She actually purchased the seeds via the internet after reading about the suicidal effects of the seeds.

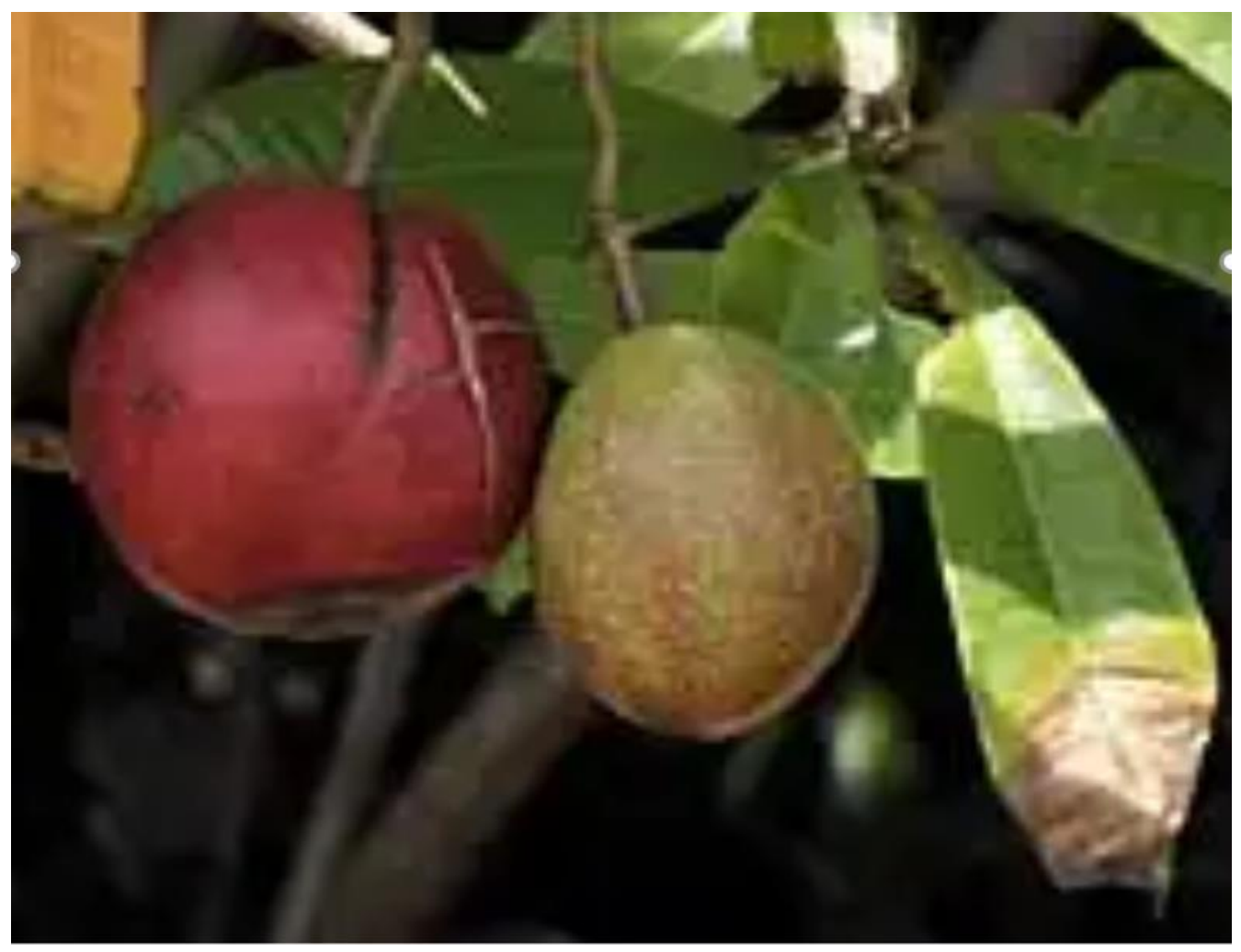

Figure 1: showing the Cerbera odollam fruit (special thanks to Gisen, Wim and Stephen Wulffraat, Max Zieren and Lisesbeth Scholten. 2006. Mangrove Guidebook for Southeast Asia)

She was in atrial fibrillation with a rate above 100 per minute and her blood pressure was $120 / 80 \mathrm{mmHg}$ when she first arrived in the 
emergency department(ED) approximately 12 hours after eating these seeds. Subsequently in the ED she had repeated episodes of vomiting and complained of acute abdominal pain and oral charcoal was not given. The first 12 leads ECG done showed a rhythm with an atrial fibrillation with a rate of 100 to 110 per minute, (figure 2).

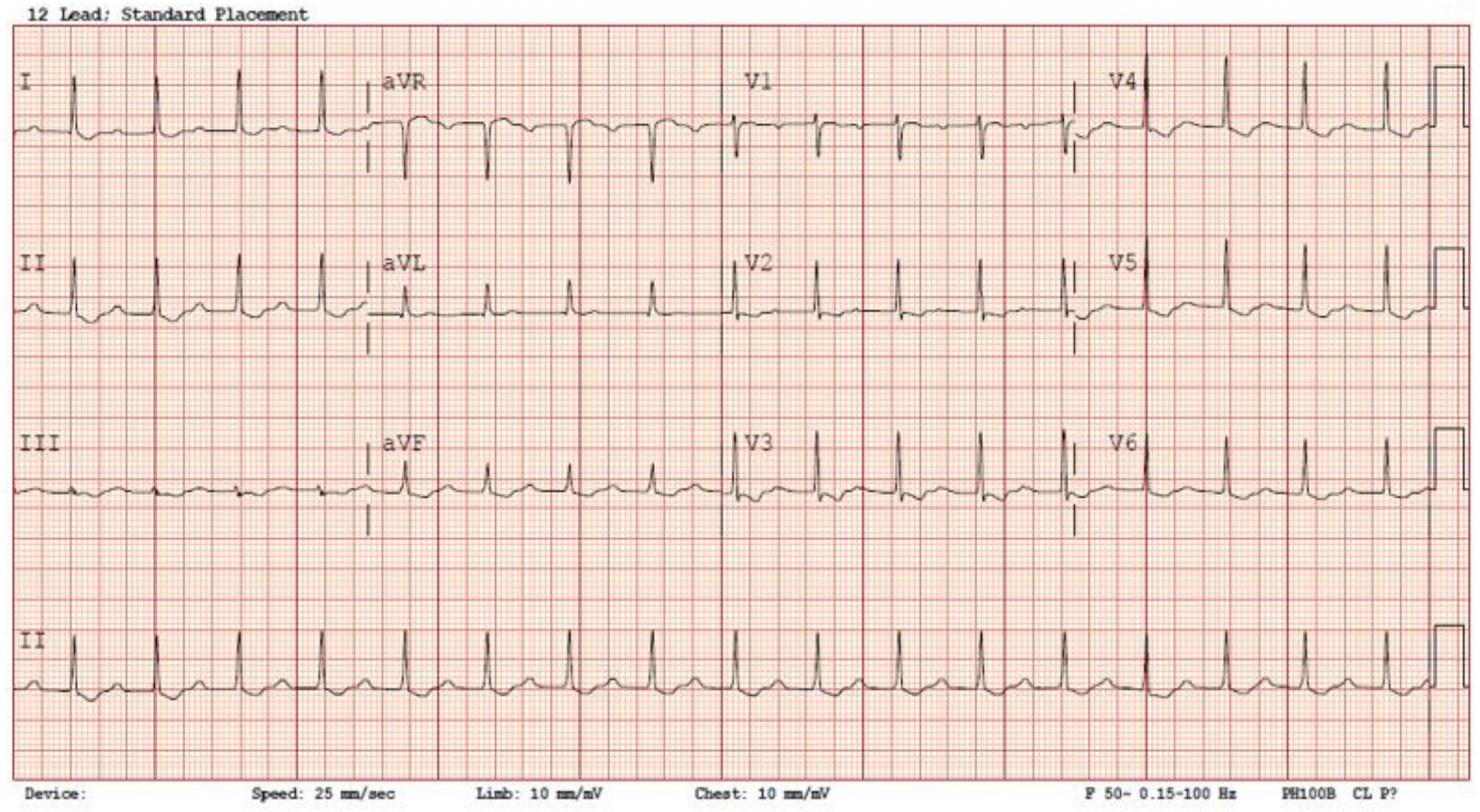

Figure 2: ECG with Atrial fibrillation

The hospital's laboratory was unable to measure cerberin level which is a type of cardiac glycosides. The digoxin level was done as a surrogate marker of cerberin toxicity. She was given $200 \mathrm{mg}$ of digoxin specific immune Fab fragments after the level of Potassium came back as 5.3 $\mathrm{mmol} / \mathrm{l}$ and her digoxin level was $1 \mathrm{ng} / \mathrm{ml}$. She responded to the treatment and got back into sinus rhythm and was 2 hours post admission as seen in figure 3 ECG.

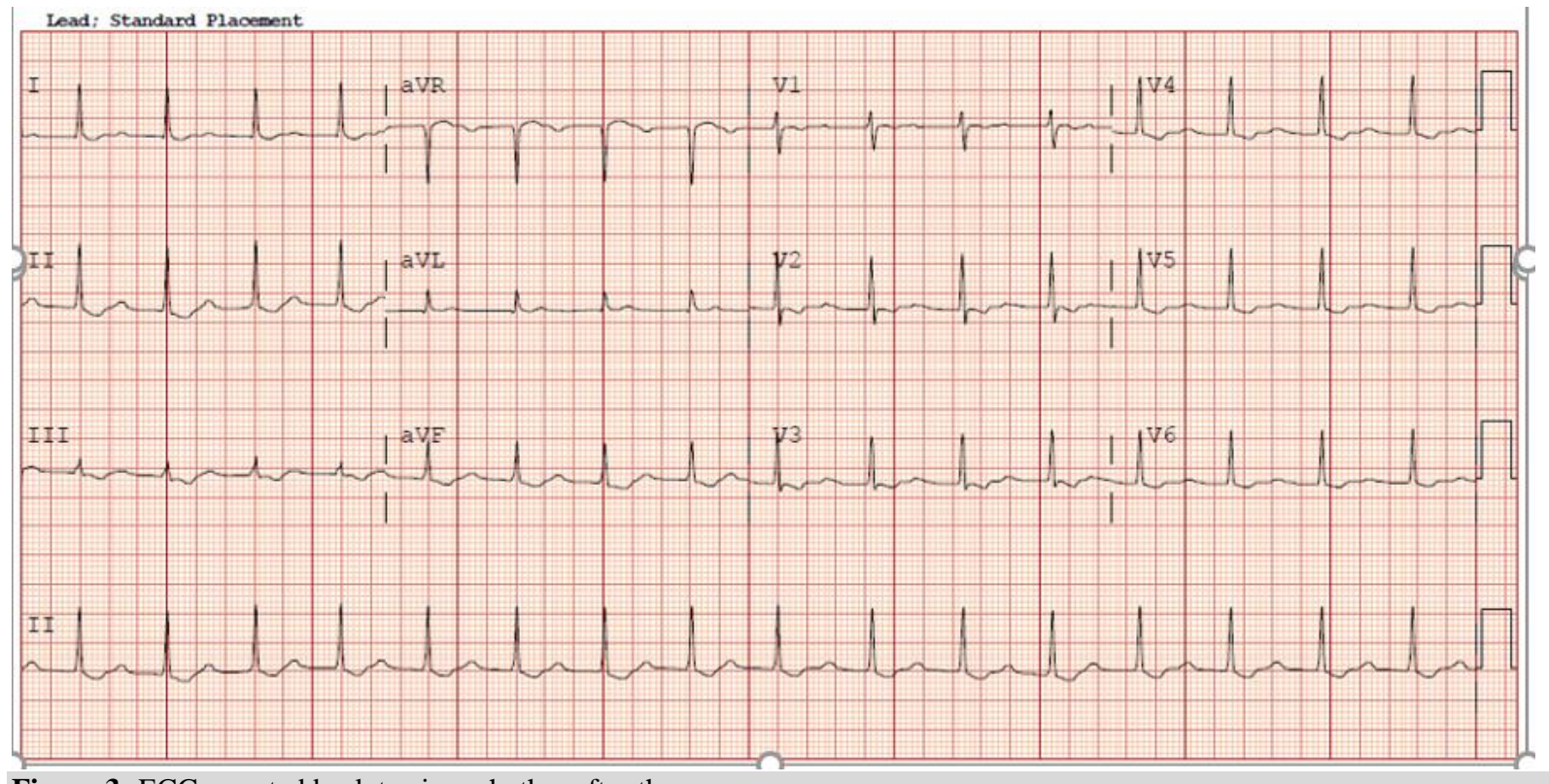

Figure 3: ECG reverted back to sinus rhythm after therapy 


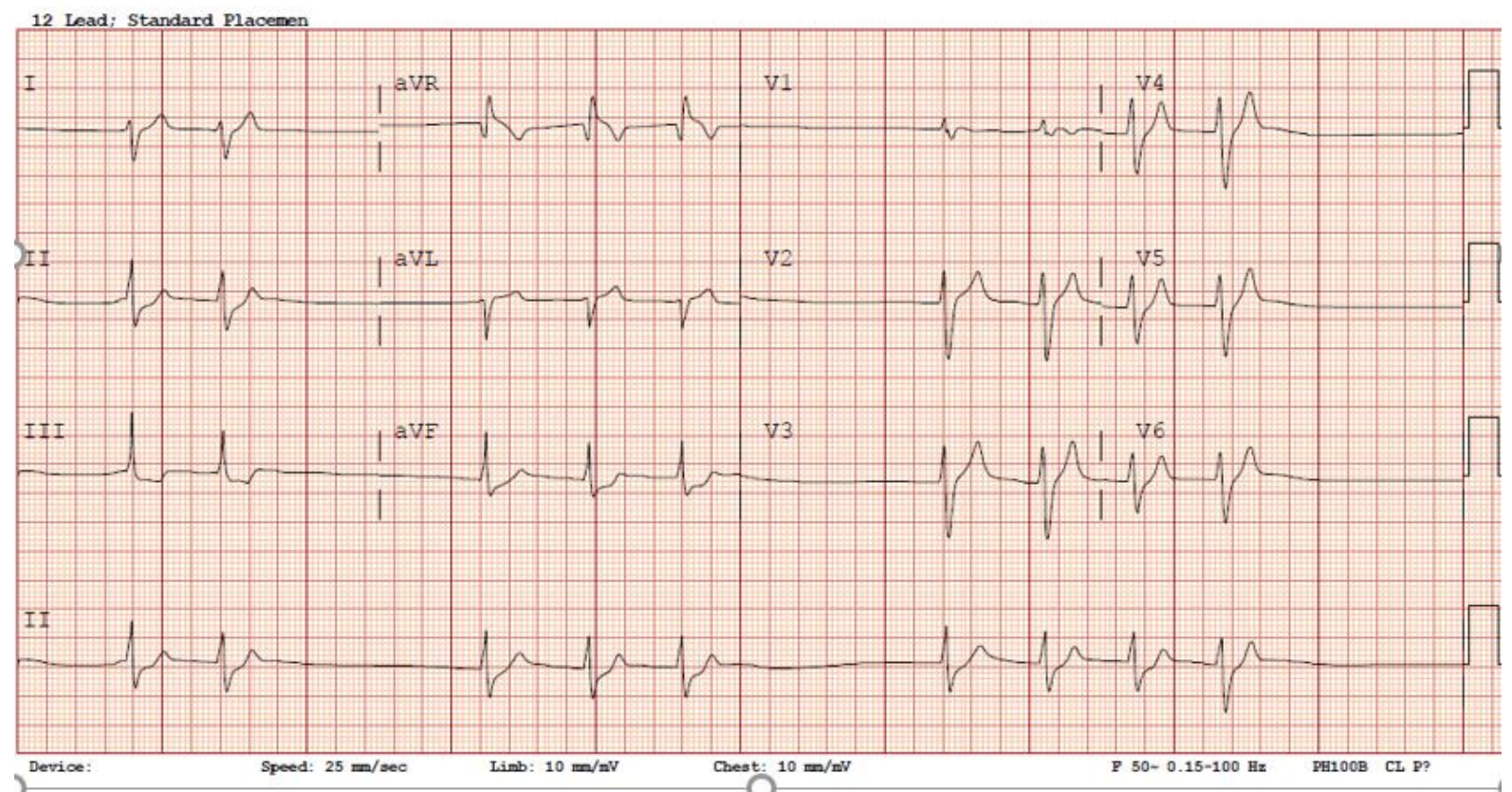

Figure 4: ECG showing brady arrhythmia

She was persistently in bradycardia despite a total of $2.4 \mathrm{mg}$ of atropine given intravenously. The dialysis catheter was inserted immediately and continuous renal replacement therapy was started as soon as she reached the ICU. She also received another $200 \mathrm{mg}$ of of digoxin specific immune Fab fragments and intravenous lipofundin as well. The patient however didn't improve and instead she showed widened QRS complexes which progressed to ventricular fibrillation prior to asystole, figure 5. She received 2 full hours of external cardiac compression and ventilator support before she was pronounced dead. This patient developed clinical evidence of arrhythmia despite a total of $400 \mathrm{mg}$ digoxin specific immune Fab fragments, $500 \mathrm{ml}$ of lipofundin $20 \%$ and hemodialysis. All of which didn't manage to reverse the toxicity of the cardiac glycoside from the kernels.

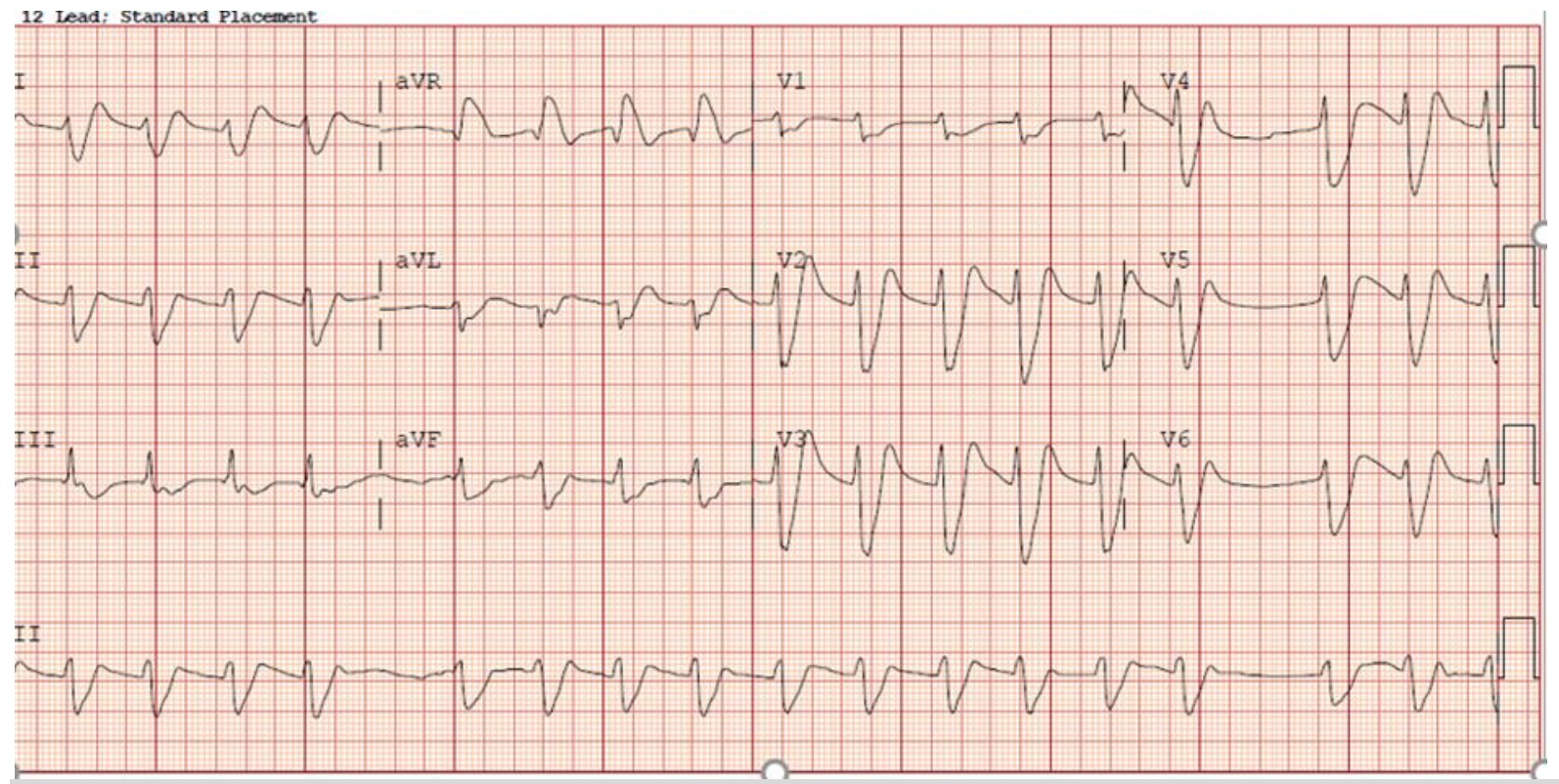

Figure 5: final ECG showing widened QRS complexes before she collapsed.

\section{Discussion}

It has been to my best knowledge that a suicidal case involving the kernel of Cerbera odollam has never been reported in Singapore.

For generations mothers in Singapore have warned their children about consuming this Pong Pong fruit but the toxicity of the kernel was never highlighted. These seeds contain active cardiac glycosides, cerberin, cereberoside and odollin and can result in fatal dysrhythmias similar to digoxin toxicity.

This patient was able to obtain information about this toxic fruit and was also able to make her purchase via the internet which was marketed as

a suicidal fruit.

The patient mentioned in our case report had similar symptoms and clinical presentations as other patients mentioned in other case reports $[2,3,4,5]$. She presented with symptoms of abdominal and vomiting and subsequently arrhythmia and hyperkalemia. She also collapsed 24 hours after eating the seed despite all the measures taken to reduce the toxicity of the cardiac glycoside. As in other case reports, hyperkalemia is 
associated with very high mortality and in this case may have precipitated the bradycardia and subsequent ventricular fibrillation. The measured digoxin of $1 \mathrm{ng} / \mathrm{ml}$ may not truly reflect the severity of cardiac glycoside toxicity in this patient even though in other series of poisoning all patients who died had a digoxin level above $1.0 \mathrm{ng} / \mathrm{ml}$. The only method of identifying cardiac glycoside is by thin-paper chromatography and unfortunately this may not easily available in most general hospitals.

It is a challenge managing this patient who had gone into cardiac arrest as the underlying toxins cannot easily cleared from the body. As highlighted the actual dosage of anti-digoxin immune Fab is unknown for cardiac glycosides as the current dosing is based on that digoxin measured in the plasma. Intravenous liopfundin 20\% was also mentioned in other case reports as a possible antidote and we had also attempted to use it in this patient but unfortunately it was not shown to be effective $[4,5,6,7]$ It was initially used for treating local anaesthetic toxicity such as bupivacaine but its usage as an antidote has been expanded to other drugs but at this stage no strong recommendation for digoxin toxicity has been established.

The use of transcutaneous pacing was considered but the inhibition of the Na-K ATPase pump may cause poor nerve conduction and render it ineffective.

ECMO was considered as a possible temporizing measure but the plan was abandoned. This is because the patient had received intravenous lipofundin $20 \%$ infusion which may increase fat deposition in the membrane of the VA-ECMO and increased blood clot formation [8].
Ingestion of the Cerbera odollam seeds can cause fatal cardiac glycoside toxicity. Unfortunately, this seeds are easily available in Singapore and also available via internet purchase. It is also sold as a form of decorative ornaments.

The other types of related cardiac glycoside toxicity can also arise from plants such as yellow oleander, foxglove and herbal dietary supplements $[1,2,3]$

Cardiac glycoside binds to and inhibits cellular $\mathrm{Na} / \mathrm{K}$-ATPase (the sodium/potassium pump). This pump transport sodium out of the cell and potassium into the cell necessary for action potentials in exciting nerves and muscles. When the pump is blocked, sodium accumulates inside the cell and this leads to an increase of intracellular calcium and extracellular potassium. The increase of calcium leads to an increase in heart contractility. In a normal healthy patient this forces the heart to work harder and can lead to arrhythmia. Hyperkalaemia can also precipitate brady arrhythmia which is highlighted in this case.

Digoxin specific Fab fragments are digoxin specific antibody Fab fragments which are purified from sheep plasma and they bind rapidly to digoxin. Fab fragments also diffuse into the interstitial space where they bind to digoxin in the tissues and as a result, the free digoxin level is rapidly reduced, creating a favorable concentration gradient for the efflux of digoxin out of the cells and into the extracellular fluid where it binds to digoxin specific fragments. The bounded digoxin cannot bind with inhibitory site on the alpha subunit of Na-K ATPase pump in the cell wall.

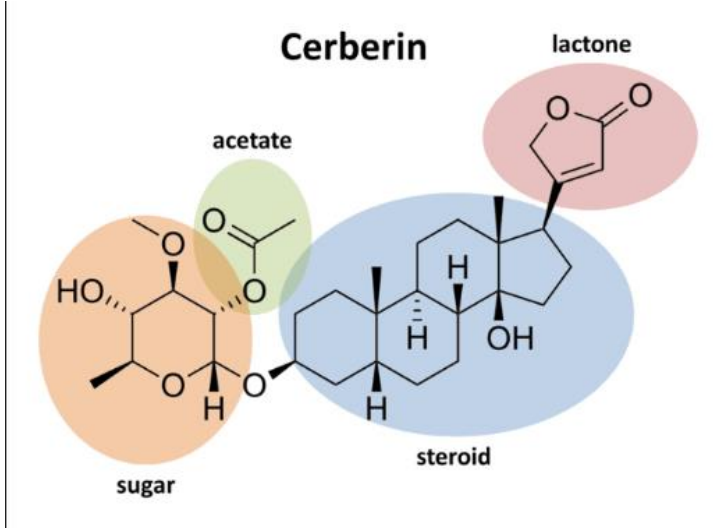

\section{Digoxin}

Figure 6

The molecular structures of the cardiac glycoside, ceberin and digoxin showed a lot of structural differences and these differences may be the cause why the cardiac glycoside may not bind as well as digoxin to the anti-digoxin immune Fab, figure 6 . The effectiveness of the antidote on cerberin has never been well studied or reported.

The pharmacokinetic and dynamic of these cardiac glycosides from these kernels are not well studied. Oral absorption may be enhanced or delay depending whether it was taken with or without any other food. It is also not known if all the different cardiac glycosides have the same toxicities.

\section{References}

1. Antman EM et al. (1990) Treatment of 150 cases of life threatening digitalis intoxication with digoxin specific Fab antibody fragments. Final report of a multicenter study. Circulation 81:1744
Cardiac glycoside is associated with high mortality as seen in the other case reports and also in our patient. More studies need to be done about these various cardiac glycosides and also their pharmacodynamics and pharmacokinetic properties. More education and preventive measures must be in place to prevent further incidence of such poisoning in the future.

The post mortem report was not available at the point of this report and it may provide further information about the structural changes associated with the myocardium as a result of the cardiac glycoside toxicity.

2. Gaillard Y et al. (2004) Cerbera odollam: a 'suicide tee' and cause of death in the state of Kerala, India. J Ethnopharmacol. 95(2-3):223-226 
3. Eddleston M et al. (2008) Fatal Injury in Eastern Sri Lanka with special reference to cardenolide self-poisoning with Cerbera manghas fruits. Clin Toxicol.(Phila). 46(8):745-748

4. Wu IL et al. (2017) Fatal cardiac glycoside poisoning due to mistaking Foxglove for Comfrey. 55(7):670-673

5. Gunja N., Graudins A. (2011) Management of cardiac arrest following poisoning. Emerg Med Australas. 23(1):16-22

6. Sophie Gosselin et al. (2016) Evidence-based recommendations on the use of intravenous lipid emulsion therapy in poisoning. Clin Toxicol. 54(10):899-923
7. Bryan D. Hayes et al. (2016) Systemic review of clinical adverse events reported after acute intravenous lipid emulsion administration. Clin Toxicol. 54(5):365-404

8. Hw Lee Min D. Lee et al. (2015) What are the adverse effects associated with the combined use of intravenous lipid emulsion and extracorporeal membrane oxygenation in the poisoned patient? Clin Toxicol. 53(3):145-150 